REVIEW ARTICLE

\title{
Chemicals as the Sole Transformers of Cell Fate
}

\author{
Behnam Ebrahimi \\ Yazd Cardiovascular Research Center, Shahid Sadoughi University of Medical Sciences, Yazd, Iran
}

Forced expression of lineage-specific transcription factors in somatic cells can result in the generation of different cell types in a process named direct reprogramming, bypassing the pluripotent state. However, the introduction of transgenes limits the therapeutic applications of the produced cells. Numerous small-molecules have been introduced in the field of stem cell biology capable of governing self-renewal, reprogramming, transdifferentiation and regeneration. These chemical compounds are versatile tools for cell fate conversion toward desired outcomes. Cell fate conversion using small-molecules alone (chemical reprogramming) has superiority over arduous traditional genetic techniques in several aspects. For instance, rapid, transient, and reversible effects in activation and inhibition of functions of specific proteins are of the profits of small-molecules. They are cost-effective, have a long half-life, diversity on structure and function, and allow for temporal and flexible regulation of signaling pathways. Additionally, their effects could be adjusted by fine-tuning concentrations and combinations of different small-molecules. Therefore, chemicals are powerful tools in cell fate conversion and study of stem cell and chemical biology in vitro and in vivo. Moreover, transgene-free and chemical-only transdifferentiation approaches provide alternative strategies for the generation of various cell types, disease modeling, drug screening, and regenerative medicine. The current review gives an overview of the recent findings concerning transdifferentiation by only small-molecules without the use of transgenes.

Keywords: Small-molecule, Cellular reprogramming, Transdifferentiation, Regenerative medicine

\section{Introduction}

From decades ago, it has been known that cell fate determination is reversible $(1,2)$. After the advent of induced pluripotent stem cell (iPSC) technology (3-5), this topic has attracted considerable attention, leading to the tremendous advancement of the reprogramming arena. Direct lineage conversion or transdifferentiation can be induced by the forced expression of lineage-specific tran-

\footnotetext{
Accepted for publication March 24, 2016, Published online May 30, 2016 Correspondence to Behnam Ebrahimi

Yazd Cardiovascular Research Center, Afshar Hospital, Jomhouri Boulevard, Yazd 8917945556, Iran

Tel: +98-3535231421, Fax: +98-3535231421

E-mail: bhnmebrahimi@yahoo.com, ebrahimi.b@ssu.ac.ir

(c) This is an open-access article distributed under the terms of the Creative Commons Attribution Non-Commercial License (http://creativecommons.org/ licenses/by-nc/4.0/), which permits unrestricted non-commercial use, distribution, and reproduction in any medium, provided the original work is properly cited.
}

scription factors, bypassing pluripotent state and its associated risks (6). Notably, to describe conversion of a terminally differentiated cell type into another, different terms are used for the same concept, including direct reprogramming, direct lineage conversion or transdifferentiation.

Reprogramming techniques conventionally use viral vectors encoding transcription factors to induce fate conversion $(6,7)$. However, the use of genetic materials in direct reprogramming methods is associated with safety-related concerns due to the introduction of exogenous DNA in the host genome. This limits potential clinical applications of direct reprogramming strategy and its products (6). Reducing the number of transcription factors or their omission has been investigated to increase the feasibility of reprogramming methods and safety of the generated cells $(6,8,9)$. Therefore, developing strategies that avoid genetic manipulations is more desirable. Various non-integrating techniques have been developed to overcome safety-related concerns (10-15). Among different integra- 
tion-free techniques, direct reprogramming by using small-molecules (chemical reprogramming) might have some advantageous over other methods. Chemical strategy displays promise for manipulation of cell fate because small-molecules are cell permeable, cost-effective, easy to use, non-integrative, and their effects are reversible. Thus, chemicals can be considered as an alternative to transcription factors because they are non-immunogenic and easy to manipulate and standardize (16-19).

Small-molecules have been used to promote differentiation and to facilitate direct reprogramming $(9,20)$. Recently, different groups independently demonstrated the dispensability of transgenic reprogramming factors in cell fate conversion between two differentiated cell types using small-molecules alone (19, 21-31). Chemical cocktails have been successful in conversion of somatic cells into induced pluripotent stem cells (iPSCs) (25, 28-30), cardiomyocyte (27), endothelial cells (24), neural progenitor cells (NPCs) (21), or neurons $(19,22,31)$. Therefore, chemical reprogramming is a new paradigm for studying cell fate conversion.

Transdifferentiation using a chemical-only approach can be a safe and efficient method for the production of clinically relevant cell types while avoids the pluripotent state and hurdles of iPSC generation and subsequent differentiation. It also bypasses safety issues intrinsic to the use of viral vectors. These findings alleviate major technical and safety concerns raised by the forced expression of transgenes and can lead to the generation of safer cells, which are more appropriate for regenerative purposes, disease modeling, and drug discovery $(16,17)$.

There are a substantial amount of papers that have dealt with the role of small-molecules in reprogramming, transdifferentiation and differentiation $(17,18,32,33)$. The current review discusses chemical-only transdifferentiation. However, it should be noted that this is a new and growing topic in the field and there have been published few reports to date. Thus, more investigation is required to confirm current findings and to demonstrate the ability of chemical-only transdifferentiation for the generation of various cell types. Special modifications in the components of chemical cocktails may yield additional lineages in future (34). Collectively, current findings in chemical reprogramming approach provide a key starting point for the generation of relevant cell types and subtypes and their translational utility.

\section{Chemical-only transdifferentiation}

Chemical reprogramming was first demonstrated by
Deng and colleagues in the generation of chemical-induced pluripotent stem cells (CiPSCs) in 2013. They showed that a cocktail of seven small-molecules reprograms mouse somatic cells into CiPSCs (25). This finding introduced a safe route for the generation of other cell types without introducing exogenous factors.

Small-molecule-mediated transdifferentiation is a new arena of the reprogramming technology. As indicated in Table 1, hitherto, there are few reports of chemical transdifferentiation and a limited number of cell types have been reprogrammed using this approach. However, it is an exciting and growing field of research and in the near future more cell types will be chemically reprogrammed. Moreover, current fate conversions have been accomplished empirically and the underlying mechanisms of these chemical reprogramming approaches remain to be investigated. Elucidating the molecular events that underlie the trajectory of chemical transdifferentiation can assist the improvement of the process and the generation of various cell types. Interestingly, although thousands of small-molecules have been screened, small-molecules with known function in differentiation have been identified to be capable of induction of transdifferentiation (19). Therefore, expanding our knowledge of underlying mechanisms of development, differentiation and reprogramming could assist identification of other small-molecule cocktails appropriate for the production of various cell types. Moreover, these findings may suggest an unexpected state of plasticity for somatic cells and indicate that the identity of somatic cells is rather flexible than previously thought. This paper discusses chemical-only transdifferentiation of somatic cells into neurons $(19,22,26)$ and neural progenitor cells (21). Moreover, it briefly reviews single reports of chemical-only transdifferentiation toward pancreatic (23), endothelial (24) and cardiomyocyte (27) fates. Of note, these fate conversions are single pioneer reports and the reproducibility of the protocols has yet to be unanimously confirmed in different settings.

Chemical transdifferentiation approaches have been done at least in two steps, including an induction step and a maturation step $(19,22)$. Furthermore, fate conversion in some of the chemical protocols goes through a transient intermediate state (Fig. 1) (23, 24).

\section{Chemical-only production of neural cells}

Three Chinese groups have endeavored to induce neural reprogramming in human and mouse somatic cells using small-molecules alone (Fig. 1) (19, 21, 22, 26, 31).

Pei group in 2014 adopted a two steps strategy to con- 
Table 1. Different steps of chemical-only transdifferentiation protocols

\begin{tabular}{|c|c|c|c|c|c|}
\hline & Starting cells & Chemical agents (induction medium) & Differentiation/Maturation medium & Product cells & References \\
\hline 1 & $\begin{array}{l}\text { Human } \\
\text { Fibroblasts }\end{array}$ & $\begin{array}{l}\text { 5-azacytidine for } 18 \text { hours } \\
\text { (dedifferentiation step) \& culture in } \\
\text { embryonic stem cell (ESC) medium } \\
\text { for } 3 \mathrm{~h} \text { (recovery step). }\end{array}$ & $\begin{array}{l}\text { Endoderm commitment: activin A for } 7 \text { days. } \\
\text { Pancreatic lineage differentiation: retinoic } \\
\text { acid and activin A, for } 3 \text { days. } \\
\text { Maturation: B27/ bFGF/ITS }\end{array}$ & $\begin{array}{l}\text { Pancreatic } \\
\beta \text {-like cells }\end{array}$ & $(23)$ \\
\hline 2 & $\begin{array}{l}\text { MEFs, mouse } \\
\text { tail-tip fibroblasts } \\
\text { and human } \\
\text { urinary cells }\end{array}$ & $\begin{array}{l}\text { 1. VCR (V, VPA, C, CHIR99021, } \\
\text { and R, Repsox) for } 10 \text { days. } \\
\text { 2. or NLS (NaB, LiCl and SB431542) } \\
\text { 3. or TLT (TSA, Li2CO3 and } \\
\text { Tranilast) }\end{array}$ & $\begin{array}{l}\text { Neural expansion medium (NEM) } \\
\text { supplemented with heparin, EGF) } \\
\text { and bFGF for next } 7 \sim 10 \text { days. }\end{array}$ & $\begin{array}{l}\text { Chemical-induced } \\
\text { Neural Progenitor } \\
\text { Cells (ciNPCs) }\end{array}$ & $(21)$ \\
\hline 3 & $\begin{array}{l}\text { Mouse } \\
\text { fibroblasts }\end{array}$ & $\begin{array}{l}\text { Neuronal induction medium (FICB) } \\
\text { containing Forskolin, ISX9, } \\
\text { CHIR99021 and I-BET151. }\end{array}$ & $\begin{array}{l}\text { Co-culture of the induced cells with } \\
\text { primary astrocytes in maturation medium, } \\
\text { including the neuronal induction medium } \\
\text { plus } 10 \mathrm{mM} \text { Forskolin, } 20 \mathrm{ng} / \mathrm{ml} \text { BDNF, } \\
\text { and } 20 \mathrm{ng} / \mathrm{ml} \text { GDNF. }\end{array}$ & $\begin{array}{l}\text { Chemical-induced } \\
\text { neurons (CiNs) }\end{array}$ & (19) \\
\hline 4 & $\begin{array}{l}\text { Human } \\
\text { Fibroblasts }\end{array}$ & $\begin{array}{l}\text { VCRFSGY: VCR + Forskolin (F), } \\
\text { SP600125, GO6983 and Y-27632 }\end{array}$ & $\begin{array}{l}\text { The induction medium was replaced by the } \\
\text { neuron maturation medium supplemented } \\
\text { with CFD (CHIR99021, Forskolin and } \\
\text { Dorsomorphin) and extra neurotropic } \\
\text { factors (BDNF, GDNF, and NT3). }\end{array}$ & $\begin{array}{l}\text { Human } \\
\text { chemically } \\
\text { induced neurons } \\
\text { (hciNs) }\end{array}$ & $(22)$ \\
\hline 5 & $\begin{array}{l}\text { Human and } \\
\text { Mouse } \\
\text { Fibroblasts }\end{array}$ & $\begin{array}{l}\text { Poly I:C (30 ng/mL) for } 7 \text { days in } \\
\text { medium containing DMEM/FBS } \\
\text { and } 7.5 \% \text { KSR. Transdifferentiation } \\
\text { medium for } 7 \text { days: DMEM/FBS } \\
\text { and } 10 \% \text { KSR + BMP4, VEGF+ } \\
\text { and bFGF. }\end{array}$ & $\begin{array}{l}\text { Endothelial cell growth medium (EGM) } \\
\text { for } 14 \text { days: } \\
\text { VEGF, bFGF, 8-Br-cAMP. } \\
\text { Next, expansion in EGM }{ }^{\text {TM }}-2 \text { medium } \\
\text { containing SB431542 }\end{array}$ & $\begin{array}{l}\text { Induced } \\
\text { Endothelial } \\
\text { Cells (iECs) }\end{array}$ & $(24)$ \\
\hline 6 & $\begin{array}{l}\text { Human } \\
\text { cortical } \\
\text { astrocytes } \\
\text { (HA1800, } \\
\text { ScienCell) }\end{array}$ & $\begin{array}{l}\text { Cell priming: LDN193189, } \\
\text { SB431542, TTNPB and } \\
\text { Thiazovivin (Tzv) for } 2 \text { days }\end{array}$ & $\begin{array}{l}\text { CHIR99021, DAPT, valproic acid (VPA) } \\
\text { and Tzv for next } 2 \text { days. } \\
\text { Next: CHIR99021, DAPT and Tzv for } \\
\text { day } 5 \sim 6 \text {. } \\
\text { On day } 7 \sim \text { day } 8 \text {, SAG, Purmo and } \\
\text { Tzv were used to complete the } \\
\text { reprogramming process. } \\
\text { At day 9, medium replaced with } \\
\text { neurotrophic factors (BDNF, NT3, and } \\
\text { IGF-1) to promote neuronal maturation. }\end{array}$ & Induced neurons & $(26)$ \\
\hline 7 & $\begin{array}{l}\text { Neonatal } \\
\text { and adult } \\
\text { astrocytes }\end{array}$ & $\begin{array}{l}\text { 1. Culture in astrocyte medium } \\
\text { for } 48 \text { hours. } \\
\text { 2. Culture in DMEMF12 containing } \\
\text { VR (VPA, } 3 \mathrm{mM} \text {; Repsox, } 1 \mu \mathrm{M}) \\
\text { or VT (Tranilast } 100 \mu \mathrm{M}) \text { plus } \\
\text { B27, N2, BDNF }(20 \mathrm{ng} / \mathrm{ml}) \text { and } \\
\text { GDNF }(20 \mathrm{ng} / \mathrm{ml}) \text { for } 8 \text { days. }\end{array}$ & $\begin{array}{l}\text { Culture in DMEM/F12 containing B27, } \\
\text { N2 plus sonic hedgehog (400 ng/ml), } \\
\text { FGF8 (100 ng/ml), bFGF (10 ng/ml), } \\
\text { L-Ascorbic acid (20 } \mu \mathrm{M}), \text { BDNF } \\
\text { (20 ng/ml), GDNF (20 ng/ml), under } \\
\text { hypoxia for } 4 \sim 10 \text { days. }\end{array}$ & $\begin{array}{l}\mathrm{DCX}^{+} \text {neuroblasts } \\
\text { (12 day post } \\
\text { induction) and } \\
\mathrm{Tuj}^{+}{ }^{+} \text {or } \\
\mathrm{NeuN}^{+} \text {neurons } \\
\text { (18 dpi) }\end{array}$ & (31) \\
\hline 8 & $\begin{array}{l}\text { Mouse } \\
\text { Fibroblasts }\end{array}$ & $\begin{array}{l}\text { Cardiac reprogramming medium } \\
\text { (CRM): reprogramming chemicals } \\
\text { (CRFVPT) (up to day } 16 \text { for MEF } \\
\text { and day } 20 \text { for TTF): knockout } \\
\text { DMEM, FBS/KSR, N2, B27, } \\
\text { Glutamax, NEAA, } \beta \text {-mercaptoetha- } \\
\text { nol, Vitamin C. } \\
\text { CRFVPT: CHIR99021 (C); RepSox } \\
\text { (R); Forskolin (F); VPA (V); Parnate, } \\
\text { (P); TTNPB (T). } \\
\text { Enhancer: Rolipram }\end{array}$ & $\begin{array}{l}\text { Cardiomyocyte-maintaining medium (CMM): } \\
\text { CMM is composed of DMEM medium with } \\
\text { FBS, 2i (3 } \mu \mathrm{M} \text { CHIR99021 and } 1 \mu \mathrm{M} \\
\text { PD0325901), LIF, vitamin C, and insulin. } \\
\text { Efficient enhancers for TTFs: Neuregulin } 1 \\
\text { (NRG1) and granulocyte-colony stimulat- } \\
\text { ing factor (G-CSF). }\end{array}$ & $\begin{array}{l}\text { Chemical-induced } \\
\text { cardiomyocyte- } \\
\text { like cells (CiCMs) }\end{array}$ & $(27)$ \\
\hline
\end{tabular}




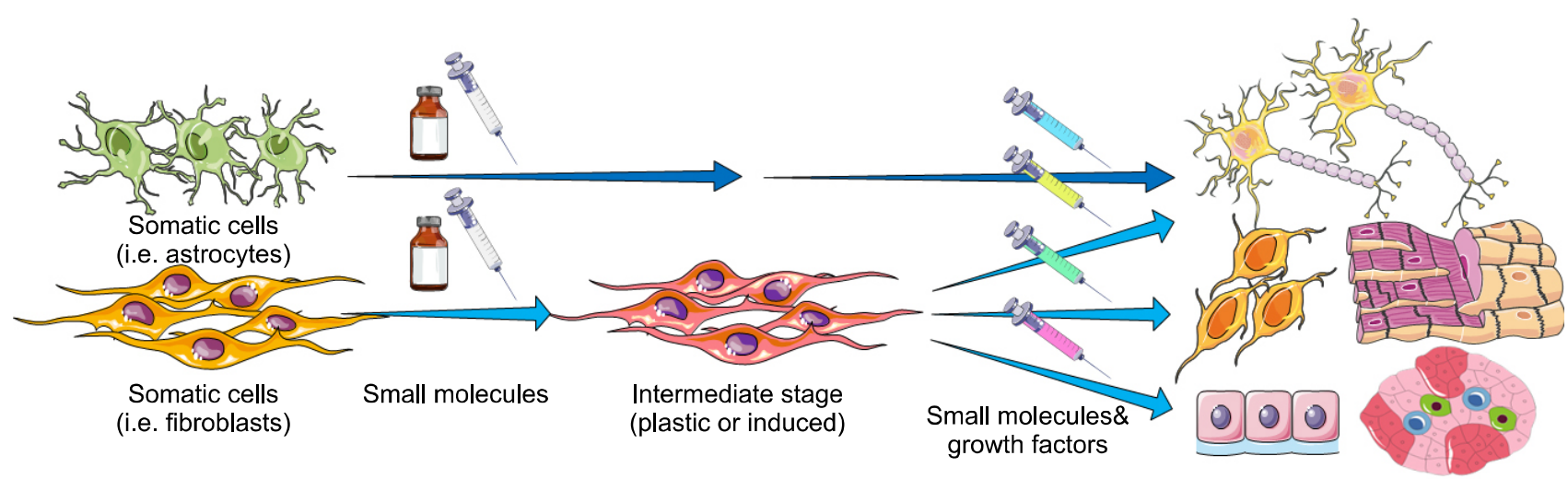

Fig. 1. Current progress in chemical-only transdifferentiation. A chemical cocktail induces the starting cells into an intermediate or immature state. Then, the immature cells are converted into different mature and progenitor cells (e.g. neurons, neural progenitor cells, neuroblasts, cardiomyocytes, endothelial cells, and pancreatic $\beta$-like cells) by small-molecules and growth factors in a stepwise manner. The intermediate state in the figure is indicative of the induced cells that are immature. Upper part shows stepwise chemical-only transdifferentiation of astrocytes into neuroblasts and neurons. Another paradigm is that the starting cells are directed toward a plastic state by specific chemicals and then they are differentiated into certain lineages by specific soluble signals (i.e. small-molecules and growth factors).

vert mouse fibroblasts and human urinary cells into true neural progenitor cells (NPCs) under a physiological hypoxic condition and without introducing exogenous factors (21). They used a chemical cocktail, namely VCR (Valproic acid (VPA), CHIR99021, and Repsox) to induce neural reprogramming. The two major steps include induction of an initial transition state using VRC/hypoxia and then lineage specification using maturation signals. Small-molecules VPA, CHIR99021 and Repsox are inhibitors of HDACs, GSK-3 and TGF- $\beta$ kinase pathways, respectively (Table 1). Findings showed that inhibition of these pathways by alternative inhibitors (Table 1) results in the same conversion process, indicating the important roles of these pathways in the successful transition of fibroblasts into NPCs (21). In their study, Cheng et al. used VCR, which are a part of CiPSC production cocktail (25, 29) (Table 2) that may induce an intermediate unstable stage appropriate for induction of a progenitor state under lineage-specific conditions (21).

Most recently, Pei and colleagues in another work indicated that a cocktail of seven small-molecules, by combinatorial modulation of multiple signaling pathways, efficiently converts human fibroblasts into functional neuronal cells without passing through a progenitor stage (22). Indeed, they promoted their previous protocol (VCR) (21) by the addition of chemicals known to promote neuronal differentiation of NPCs (22).

They found that addition of four small-molecules, including Forskolin (activator of adenylate cyclase, F), SP600125 (JNK inhibitor, S), GO6983 (PKC inhibitor, G) and Y-27632 (ROCK inhibitor, Y) to the VCR (collectively
VCRFSGY) potently converts human fibroblasts into neuronal cells (22). To improve neuronal cell survival and maturation, they replaced induction medium containing VCRFSGY with maturation medium containing CHIR99021 (C), Forskolin (F), and Dorsomorphin (D) and extra neurotropic factors (BDNF, GDNF, and NT3) (22) (Table 1). The products of this induction system were mostly glutamatergic neurons. Possibly, modified chemical cocktails may generate different neuronal subtypes (22).

Pei and colleagues showed that chemical-induced NPCs (ciNPCs) converted from mouse embryonic fibroblasts (MEFs) keep a degree of residual fibroblast epigenetic memory (21), indicating the need for more robust protocols to be capable of erasure of the native program in this progenitors. By contrast, they indicated that VCRFSGY induction protocol effectively suppresses fibroblast-specific genes and establishes an authentic neuronal identity (22).

Interestingly, this chemical approach generated human chemical-induced neuronal cells (hciNs) from familial Alzheimer's disease patients (22). This finding shows the capability of this chemical induction protocol for the generation of patient-specific neuronal cells that could be useful for disease modeling and drug screening (22).

Recently, $\mathrm{Li}$ et al. demonstrated that a minimal set of four small-molecules, including Forskolin, ISX9, CHIR99021 and I-BET151 (FICB) robustly converts mouse fibroblasts into functional neurons (Table 1 and 2) with a yield of up to $90 \%$ (19). Indeed, this chemical cocktail induced reprogramming via disruption of the fibroblast program using I-BET151 and induction of neuronal cell fate mostly by ISX9. To mature chemically induced neurons (CiNs), 
Table 2. Different small-molecules that have been used in chemical-only transdifferentiation (small molecules that have a role in production of CiPSCs are included to show their importance in different chemical protocols)

\begin{tabular}{|c|c|c|c|}
\hline Small-molecule & Effect & Role in generation of & Reference \\
\hline \multirow[t]{3}{*}{ Forskolin } & \multirow[t]{3}{*}{ Activator of adenylate cyclase } & Human chemically induced neurons (hciNs) & $(22)$ \\
\hline & & Mouse chemical-induced neurons (CiNs) & (19) \\
\hline & & Mouse CiPSC & $(25,28-30)$ \\
\hline SP600125 & JNK (Jun N-terminal kinase) inhibitor & hciNs & $(22)$ \\
\hline GO6983 & PKC (Protein kinase C) inhibitor & hciNs & (22) \\
\hline Y-27632 & $\begin{array}{l}\text { ROCK (Rho-associated protein kinase) } \\
\text { inhibitor }\end{array}$ & hciNs & (22) \\
\hline \multirow[t]{4}{*}{ VPA (valproic acid) } & \multirow[t]{4}{*}{ HDAC inhibitor } & $\begin{array}{l}\text { Mouse Chemical-induced cardiomyocyte-like } \\
\text { cells (CiCMs) }\end{array}$ & (27) \\
\hline & & $\begin{array}{l}\text { Human and mouse chemical-induced Neural } \\
\text { Progenitor Cells (ciNPCs) }\end{array}$ & (21) \\
\hline & & Human induced neurons & (26) \\
\hline & & Mouse CiPSC & $(25,28-30)$ \\
\hline \multirow[t]{5}{*}{ CHIR99021 } & \multirow[t]{5}{*}{ An inhibitor of GSK-3 } & Human and mouse ciNPCs & (21) \\
\hline & & Human hciNs & (22) \\
\hline & & Human ciNPCs & (26) \\
\hline & & Mouse CiCMs & $(27)$ \\
\hline & & Mouse CiPSC & $(25,28-30)$ \\
\hline \multirow[t]{3}{*}{ Repsox (or 616452) } & \multirow[t]{3}{*}{ An inhibitor of TGF- $\beta$ pathways } & Human and mouse ciNPCs & (21) \\
\hline & & Mouse CiCMs & $(27)$ \\
\hline & & Mouse CiPSC & $(25,28-30)$ \\
\hline $\begin{array}{l}\mathrm{LiCl} \\
\text { (Lithium chloride), }\end{array}$ & An inhibitor of GSK-3 kinases & Human and mouse ciNPCs & $(21)$ \\
\hline \multirow[t]{3}{*}{ SB431542 } & \multirow[t]{3}{*}{ A specific TGF- $\beta$ receptor inhibitor } & Human and mouse ciNPCs & (21) \\
\hline & & Human and mouse Induced Endothelial Cells (iECs) & (24) \\
\hline & & Induced neurons & (26) \\
\hline TSA (Trichostatin A) & HDAC inhibitor & Human and mouse ciNPCs & (21) \\
\hline Sodium Butyrate (NaB) & HDAC inhibitor & ciNPCs & (21) \\
\hline $\begin{array}{l}\text { Li2CO3 } \\
\text { (Lithium carbonate) }\end{array}$ & An inhibitor of GSK-3 $\beta$ & Human and mouse ciNPCs & (21) \\
\hline \multirow[t]{2}{*}{ Tranilast } & \multirow{2}{*}{$\begin{array}{l}\text { An inhibitor of transient receptor } \\
\text { potential vanilloid } 2 \text { (TRPV2) channels } \\
\text { and receptors of platelet-derived growth } \\
\text { factor (PDGFRs). A TGF- } \beta \text { inhibitor }\end{array}$} & Human and mouse ciNPCs & (21) \\
\hline & & $\mathrm{DCX}^{+}$neuroblasts and $\mathrm{Tuj}^{+}$or $\mathrm{NeuN}^{+}$neurons & (31) \\
\hline ISX9 & $\begin{array}{l}\text { Facilitates neural differentiation by } \\
\text { increasing expression of transcription } \\
\text { factor NeuroD1 }\end{array}$ & Mouse chemical-induced neurons (CiNs) & (19) \\
\hline I-BET151 & BET bromodomain inhibitor & Mouse CiNs & (19) \\
\hline Poly I:C & $\begin{array}{l}\text { Polyinosinic-polycytidylic acid, activator } \\
\text { of toll-like receptor } 3 \text { pathway }\end{array}$ & Human and mouse iECs & (24) \\
\hline $\begin{array}{l}\text { 8-Br-cAMP } \\
\text { (8-bromoadenosine-3': } \\
\text { 5'-cyclic monophosphate) }\end{array}$ & $\begin{array}{l}\text { An a brominated analog of cAMP; } \\
\text { activator of protein kinase } \mathrm{A}\end{array}$ & Human and mouse iECs & (24) \\
\hline $\begin{array}{l}\text { DAPT (N-[N-(3,5-difluoro- } \\
\text { phenacetyl)-L-alanyl]- } \\
\text { S-phenylglycine t-butyl } \\
\text { ester) }\end{array}$ & $\begin{array}{l}\text { An inhibitor of } \gamma \text {-secretase; } \\
\text { An inhibitor of Notch signaling. } \\
\text { Facilitates neuronal differentiation }\end{array}$ & Human induced neurons & (26) \\
\hline $\begin{array}{l}\text { SAG } \\
\text { (Smoothened agonist) }\end{array}$ & $\begin{array}{l}\text { Agonist of protein Smoothened, a key } \\
\text { part of the Hedgehog signaling path- } \\
\text { way; inducespathway activation }\end{array}$ & Human induced neurons & (26) \\
\hline Purmo (Purmorphamine) & $\begin{array}{l}\text { An agonist of protein Smoothened (Smo) } \\
\text { that activates Hedgehog pathway }\end{array}$ & Human induced neurons & (26) \\
\hline
\end{tabular}


Table 2. Continued

\begin{tabular}{|c|c|c|c|}
\hline Small-molecule & Effect & Role in generation of & Reference \\
\hline LDN193189 & $\begin{array}{l}\text { Inhibitor of BMP type I receptors ALK2 } \\
\text { and ALK3. }\end{array}$ & Human induced neurons & $(26)$ \\
\hline TTNPB & $\begin{array}{l}\text { A synthetic retinoic acid receptor (RAR) } \\
\text { ligand; activates retinoic acid receptors }\end{array}$ & $\begin{array}{l}\text { Mouse CiCMs } \\
\text { Human induced neurons } \\
\text { Mouse CiPSC }\end{array}$ & $\begin{array}{r}(27) \\
(26) \\
(25,28)\end{array}$ \\
\hline $\begin{array}{l}\text { Tranylcypromine } \\
\text { (Parnate) }\end{array}$ & $\begin{array}{l}\text { An epigenetic modifier that inhibits } \\
\text { lysine-specific demethylase } 1 \text { (LSD1)) }\end{array}$ & $\begin{array}{l}\text { Mouse CiCMs } \\
\text { Mouse CiPSC }\end{array}$ & $\begin{array}{c}(27) \\
(25,28-30)\end{array}$ \\
\hline 5-azacytidine & Inhibitor of DNA methyltransferase & $\begin{array}{l}\text { Human pancreatic } \beta \text {-like cells } \\
\text { Mouse CiPSC }\end{array}$ & $\begin{array}{l}(23) \\
(29)\end{array}$ \\
\hline $\begin{array}{l}\text { ITS (insulin-transferrin- } \\
\text { selenium) }\end{array}$ & $\begin{array}{l}\text { A media supplement containing human } \\
\text { insulin, human transferrin, and sodium } \\
\text { selenite. }\end{array}$ & Human pancreatic $\beta$-like cells & (23) \\
\hline
\end{tabular}

they were co-cultured with primary astrocytes in a maturation medium. Li et al. showed that the majority of the CiNs were the excitatory, glutamatergic neurons (about $45.8 \%$ ), and about $20.8 \%$ of them were inhibitory subtype. A characteristic of this approach is that the cells undergoing transdifferentiation disrupted the program of the starting cells and gained a transcriptional profile of the intended cells in the early stages within 24 hours. Moreover, it has been indicated that CiNs are directly reprogrammed from fibroblasts bypassing a transitional proliferative stage (Fig. 1) (19).

The studies of $\mathrm{Hu}$ et al. (22) and Li et al. (19) resulted in neuronal transdifferentiation of human and mouse fibroblasts, respectively, using small-molecules alone. In these studies, CHIR99021 and Forskolin were common in both cocktails, indicating the importance of GSK3 inhibition and cyclic AMP stimulation in neuronal fate conversion.

Different assays (e.g. transcriptional profile, morphological, and electrophysiological properties), showed that CiNs produced by both cocktails are functional and similar to the stem cell-derived neurons and transcription factor-induced neurons $(19,22)$. Both groups indicated that most of their CiNs are excitatory, glutamatergic neurons and that cholinergic or dopaminergic neurons were absent. Both cocktails silenced the fibroblast program. Furthermore, both studies indicated that fate conversions occurred directly and no progenitor state was detected. Findings showed that in both cocktails, small-molecules exerted their effects in a synergistic manner to do the neuronal conversion. These findings show that a well-designed chemical protocol can directly and efficiently convert mouse or human fibroblasts into functional neurons within few days.

Astrocytes are an ideal donor cell course for trans- differentiation into neurons. Astroglial cells have been directly reprogrammed into functional neurons both in vitro $(35,36)$ and in vivo $(35,37-40)$ using the viral-based expression of transcription factors. In 2014, Chen and colleagues showed that reactive glial cells can be directly converted into functional neurons in vivo by the transcription factor, NeuroD1 (35). Most recently they reported that a small-molecule cocktail (LDN193189, SB431542, TTNPB, Tzv, CHIR99021, VPA, DAPT, SAG, and Purmo) converts human astrocytes into fully functional neurons in vitro in 8-10 days when administered in a stepwise manner (Table 1) (Fig. 1) (26). For maturing astrocyte-converted neurons, they used neurotrophic factors (BDNF, NT3, and IGF-1). Mechanistically, this chemical reprogramming protocol epigenetically silenced glial genes and transcriptionally activated neuronal genes (e.g. NGN2 and NEUROD1) (26). Interestingly, chemically reprogrammed human neurons generated from astrocytes survived for $>5$ months in vitro and $>1$ month in the mouse brain in vivo (26). This chemical astrocyte-neuron reprogramming strategy mostly results in forebrain glutamatergic neurons as the major subtype. Therefore, different small-molecules or different strategies should be adopted for the generation of other types of neurons (26).

Pei and colleagues recently developed a chemical recipe that can convert neonatal and adult mouse astrocytes into neuronal cells in vitro (Fig. 1) (31). They used their previous VCR cocktail with slight modifications. They found that VPA is sufficient to induce fate conversion, but with lower efficiency and that the efficiency of VR (VPA and Repsox) was similar to that of VCR. Similar results were observed by replacement of Repsox with Tranilast ( $T$, a TGF- $\beta$ inhibitor and an antiallergic drug). These chemical cocktails converted mouse astrocytes into $\mathrm{DCX}^{+}$neuroblasts and $\mathrm{Tuj}^{+}$or $\mathrm{NeuN}^{+}$neurons. Interestingly, the 
mature neurons converted from astrocytes were functional with action potentials and postsynaptic currents. This finding shows that chemicals are capable of driving transdifferentiation of mouse astrocytes into neurons in vitro through the activation of NeuroG2 and NeuroD1 expression (31).

Findings of Zhang et al. and Cheng et al. reveal that chemical approach can be a hope for the regeneration of neurons after brain injury. Indeed, these data offer the idea that the application of a chemical cocktail in situ can convert resident astrocytes into neurons, which is the ultimate goal of regenerative medicine.

The findings of Zhang et al. showed that chemical inhibition of $\mathrm{BMP} / \mathrm{TGF} \beta$, Notch, and GSK3 $\beta$ signaling pathways is fundamental for reprogramming human astrocytes into neurons (26). Interestingly, aforementioned studies showed that CHIR99021 (inhibitor of GSK3 $\beta$ ) appears to be an indispensable small-molecule for chemical conversion of most of the somatic cells into neurons. By contrast, Cheng et al. found that CHIR99021 is dispensable for chemical-induced astrocyte-to-neuron conversion in mouse cells.

Results revealed that different cell types have distinct requirements for a specific fate conversion $(19,22,26)$. Indeed, the type or origin of starting cells has a significant impact on reprogramming process and its products (41, 42). For example, an optimized protocol for conversion of human brain astrocytes into neurons has been unable to convert human spinal cord astrocytes or mouse astrocytes, suggesting specificity of this chemical reprogramming protocol for astrocytes with human brain origin (26). Therefore, it could be concluded that a specific cell type would respond to a specific set of small-molecules to undergo the intended fate conversion. Accordingly, different sets of chemicals should be optimized for the generation of different subtypes of neurons and possibly induction of regeneration in different neurological disorders.

Chen and colleagues used reprogramming chemicals in a sequential manner due to the adverse effect of simultaneous inhibition of some signaling pathways on cell survival (26). These findings show that combinatorial modulation of multiple signaling pathways could have opposing effects on reprogramming process and its efficiency. Moreover, lessons from embryonic development suggest that it would be better to adopt a stepwise strategy for chemical transdifferentiation.

Another point is that physiological hypoxia is a key component of the niche of stem cells in vivo influencing proliferation and cell-fate commitment (43). Regarding the role of hypoxia as a facilitator of neurons (31) and
NPC chemical transdifferentiation (21), examining chemical transdifferentiation protocols in low oxygen conditions and importantly in vivo would be of great interest.

\section{Chemical-only production of cardiomyocytes}

Findings have shown that cardiomyocyte-like cells can be generated by the forced expression of transcription factors (44-46) or miRNAs (47) and that small-molecules can enable cardiac transdifferentiation of fibroblasts by Oct4 alone (48). Surprisingly, in an attempt to replicate mouse CiPSC production method using CRFVPT (i.e. CHIR99021, RepSox, Forskolin, VPA, Parnate, TTNPB) cocktail (25), $\mathrm{Fu}$ et al. found infrequent beating cardiomyocytes instead of CiPSCs in their culture as early as days $6 \sim 8$ (Fig. 1) (27). Their two-stage optimization strategy showed that CRFV was the most critical cocktail for the induction of beating clusters, with RepSox (R) as the most important inducing factor, while Parnate or TTNPB was found to be dispensable (27). Moreover, small-molecules ICARIIN, PD169316 and Rolipram increased the efficiency of cardiac reprogramming (27).

Why in this study Xie and colleagues achieved cardiomyocytes (27) using CiPSCs generation protocol (25) is not fully known. This is while in their recent study (28) they repeated successfully the chemical protocol of Hou et al. (CiPSCs generation protocol) and enhanced the efficiency of CiPSC generation. However, the subsequent culture condition appears to play a critical role in driving the early intermediate cells toward iPSC or cardiomyocyte fates (27).

Results showed that chemical-mediated cardiac reprogramming goes through a cardiac precursor-like stage but not a pluripotent one and both atrial-like and ventricular-like cells were found in the culture. $\mathrm{Fu}$ et al. showed that $\mathrm{Scal}^{+}$cardiac precursor-like cells can be differentiated into smooth muscle cells and endothelial cells (27). This indicates that specific cell sub-types could be derived within a particular lineage by modifying the chemical cocktails and culture conditions.

\section{Transdifferentiation by chemical-only induction of an intermediate plastic state}

In addition to the direct reprogramming of somatic cells into different lineages by the forced expression of lineage-specific transcription factors, pluripotency transcription factors have been used to induce transdifferentiation. The late transdifferentiation technique was named cell-activation and signaling-directed (CASD) lineage conversion 
(48). In this paradigm, a brief expression of pluripotency transcription factors dedifferentiates the starting cells into an unstable and plastic state (cell-activation) and then lineage-specific differentiation signals direct them toward a specific fate (49). This transdifferentiation technique still utilizes forced expression of transgenes. An integration-free approach for induction of the CASD lineage conversion can be a chemical-only approach for induction the cell-activation step or plastic state. Interestingly, two studies have used the chemical approaches to drive somatic cell transdifferentiation using a similar methodology to the CASD lineage conversion (23). Cooke $(24,50)$ and Brevini (23) groups utilized small-molecules to induce a plastic state in donor cells to become responsive to the environmental cues and eventually to drive transdifferentiation.

Concerning the important role of DNA demethylation during early embryonic development and pluripotent reprogramming, Brevini and colleagues reported that a short-term exposure to 5-azacytidine (5-aza), a DNA methyltransferase inhibitor, in conjunction with culture in embryonic stem cell (ESC) medium can induce expression of pluripotency genes (Oct4, Sox2, Nanog and Zfp42) and a state of plasticity in human skin fibroblasts and make the cells responsive to the developmental cues (23). They showed that administration of specific differentiation signals using a three-step protocol establishes a pancreatic endocrine identity in the cells undergoing endocrine fate conversion (23). The generated $\beta$-like cells were functional in vitro and in vivo. They did not form tumor after transplantation, this property together with the patient-specific origin of the starting cells makes this transgene-free method of transdifferentiation appropriate for therapeutic applications (23).

In this transdifferentiation paradigm, the action of 5-aza is relatively similar to that of the pluripotency factors in the CASD lineage conversion. Sufficiency of a brief exposure (18 hours) to 5-aza for induction of plasticity in human fibroblasts (23) offers new ideas for refinement of the CASD approach and subsequently integration-free production of a variety of cell types from somatic cells.

Surprisingly, Lee et al. found that viral vectors in addition to being simple vehicles for transcription factors participate in pluripotent reprogramming by increasing epigenetic plasticity through the activation of toll-like receptor 3 (TLR3) signaling pathway and innate immunity responses (50). Indeed, activation of TLR3 transcriptional pathways leads to global changes in epigenetic modifiers favored histone modifications needed for activation of endogenous pluripotency network (50).

Angioblast-like cells (51) and endothelial cells (ECs)
$(52,53)$ have been produced previously using the CASD approach. Moreover, human induced ECs (iECs) have been directly generated by the forced expression of lineage-specific transcription factors (52, 54). Remarkably, Sayed et al. taking the advantage of induced plasticity through the activation of TLR3 pathway generated ECs. In this paradigm, TLR3 agonist Poly I:C together with endothelial cell differentiation signals, transdifferentiated human fibroblasts into functional ECs (Table 1). They indicated that the innate immune-mediated plasticity transdifferentiation protocol directly converts donor cells without passing through an intermediate pluripotent state (Fig. 1). Therefore, activation of TLR3 in combination with developmental cues appears to be sufficient to induce an intended transdifferentiation in somatic cells without the use of any genetic material (24).

\section{Discussion}

For a long time, it has been known that the cell fate is fluid and can be experimentally altered by the forced expression of lineage-specific transcription factors (2). Generating human iPSCs and their differentiation for the production of clinically relevant cell types is a cumbersome process and remains problematic due to the use of genetic materials in reprogramming and the presence of residual pluripotent cells in its differentiated products, which are tumorigenic (55).

Various cell types have been produced by the forced expression of lineage-specific transcription factors. Although direct reprogramming methods for the generation of desired therapeutic cells from the patient somatic cells bypass pluripotent state, they use genetic materials (6). There are safety-related concerns associated with the use of viral vectors in direct reprogramming and transdifferentiation methods, which limit their use in the clinical setting $(6,55)$.

Small-molecules have advantages that enable us to spatially and temporally control gene expression and cell fate. They are easy to combine, handle, optimize, adjust, and withdraw $(9,20)$. Selection of the proper small-molecules and adjusting their concentrations and duration in order to do precise modulation of multiple signaling pathways are critical for induction of a successful somatic cell reprogramming $(29,56)$. Recent findings have shown that transdifferentiation can be achieved without the need for ectopic expression of lineage-specific transcription factors by only application of small-molecules and growth factors $(19,21-24,26,27)$. It has been indicated that small-molecule cocktails are sufficient to activate the expression of 
special master transcription factors of an intended cell fate (19). Interestingly, chemical approaches could produce desired cells directly from patient cells in much shorter time and without safety-related concerns (22).

In a previous part, the current study reviewed chemical-only generation of neuronal cells and neural-progenitor cells from somatic cells (Table 1) (Fig. 1) (19, 21, 22, 26). Cheng et al. showed that human urinary cells (hUCs) and different sources of mouse fibroblasts can be converted into ciNPCs using VCR under physiological hypoxia (21). Moreover, they chemically converted mouse astrocytes into neurons (31).

Recently, Li et al. (19) and $\mathrm{Hu}$ et al. (22) designed chemical protocols that were successful in the generation of neuronal cells directly from human and mouse fibroblasts $(19,22)$. Moreover, Zhang et al. reported that sequential exposure to a cocktail of nine small-molecules converts cultured human astrocytes into neurons (26). Regarding the inhibitory role of native gene regulatory networks during reprogramming (57), results from different laboratories show that chemical protocols can erase the native identity of the initial cells and activate endogenous neuronal transcriptional factors to establish neuronal fate $(19,22,26)$. Chemical transdifferentiation of fibroblasts derived from patients with familial Alzheimer's disease (FAD) into hciNs represents chemical approaches as an alternative tool for the generation of patient-specific neuronal cells that could be appropriate for disease modeling and drug screening (22).

Cardiomyocyte-like cells have been generated by introduction of lineage-specific transcription factors and miRNAs both in vitro and in vivo (44, 47, 58, 59). Compared with these methods, $\mathrm{Fu}$ et al. developed a full chemical approach for the generation of cardiomyocyte-like cells (27). This chemical method of cardiomyocyte generation passes through a progenitor stage, representing the ability of this method for the generation of both progenitors and mature cardiomyocytes. Progenitor cells may be ideal for regenerative purposes because they may be more robust in surviving in the hostile graft environment, and by their limited proliferation could restore tissue function and contribute to revascularization (27).

Interestingly, findings have demonstrated that an extraembryonic endoderm (XEN)-like state is essential for small-molecule-induced pluripotent reprogramming (29, 30). However, the underlying mechanisms of chemical transdifferentiation remain insufficiently defined. Thus, more investigation is needed to elucidate molecular roadmap underlying chemical transdifferentiation. It has been demonstrated that removal of reprogramming barriers fa- cilitates the action of transcription factors during pluripotent reprogramming and significantly increase the efficiency and kinetics of the process (42). Suggestively, the enhancing strategies developed for increasing the efficiency of iPSC reprogramming (42) might be capable of enhancing the efficiency of chemical transdifferentiation approaches.

Another strategy for transdifferentiation is the induction of epigenetic plasticity in donor cells and subsequently providing developmental cues to promote lineage conversion (49). The findings of Pennarossa et al. (23) and Sayed et al. (24) suggest that experimental techniques of manipulation of innate immune signaling pathways or administration of small-molecule modifiers of epigenome could be used to induce epigenetic plasticity in somatic cells and to engineer cell fate $(23,24)$. This form of chemical transdifferentiation strategy is similar to the CASD lineage conversion, which uses iPSC transcription factors for induction of a plastic state (49). However, in contrast to the direct reprogramming technology and the CASD paradigm, these chemical methods do not use any genetic modification; this potentially allows their clinical application $(23,24)$. Considering the CASD method, lessons from in vitro differentiation of stem cells, and chemical-only reprogramming, the CASD transdifferentiation could be accomplished by small-molecules alone. Consequently, induction of a state of plasticity in somatic cells using chemicals is a technical advance for the generation of a variety of therapeutic cell types.

\section{Conclusions}

Numerous small-molecules with diverse functions have been used in the chemical production of different cell types (Table 2). Generally, small-molecules have different roles in chemical-only reprogramming approaches, including induction of plasticity, inhibition of starting cell program, activation and establishment of target cell fate, and improvement of the reprogramming efficiency. Similarly, growth factors play a critical role in induction and maturation of converted cells by modulation of signaling pathways (Table 1). Moreover, fine-tuning the number and concentration of small-molecules and growth factors is fundamental to an efficient chemical-only reprogramming approach. Suggestively, administration of reprogramming chemicals and growth factors in a stepwise manner with a relative similarity to the fate determination during embryonic development that needs more understanding of the mechanisms of the process would assist improving the efficiency, kinetics, and specificity of the chemical-only 
reprogramming.

Chemical-only approaches are more desirable for clinical applications because they avoid potential complications related to the use of genetic materials, including tumorigenicity, immune rejection, and homing behavior of the injected cells in cell transplantation therapies (6). Chemical reprogramming could be an alternative strategy to generate and investigate patient-specific cell lines. In addition to disease modeling and drug screening, chemical approaches hold great promises in regenerative medicine by induction of regeneration in vivo against different diseases (e.g. neurological or heart diseases) or injuries (22). Collectively, the findings that are discussed here are proof of principle and open new avenues for a pharmaceutical approach to cellular therapy and in vivo induced regeneration. The future may see the emergence of reprogramming drugs, which are designed for regeneration and therapeutic applications.

\section{Acknowledgments}

The author would like to thank Drs. Mohammad Hossein Soltani and Mahdieh Namayandeh from Yazd Cardiovascular Research Center for their administrative supports. This work was supported by Yazd Cardiovascular Research Center.

\section{Potential conflict of interest}

The author has no conflicting financial interest.

\section{References}

1. Gurdon JB, Laskey RA, Reeves OR. The developmental capacity of nuclei transplanted from keratinized skin cells of adult frogs. J Embryol Exp Morphol 1975;34:93-112

2. Davis RL, Weintraub H, Lassar AB. Expression of a single transfected cDNA converts fibroblasts to myoblasts. Cell 1987;51:987-1000

3. Takahashi K, Yamanaka S. Induction of pluripotent stem cells from mouse embryonic and adult fibroblast cultures by defined factors. Cell 2006;126:663-676

4. Takahashi K, Tanabe K, Ohnuki M, Narita M, Ichisaka T, Tomoda K, Yamanaka S. Induction of pluripotent stem cells from adult human fibroblasts by defined factors. Cell 2007;131:861-872

5. Yu J, Vodyanik MA, Smuga-Otto K, Antosiewicz-Bourget J, Frane JL, Tian S, Nie J, Jonsdottir GA, Ruotti V, Stewart $\mathrm{R}$, Slukvin II, Thomson JA. Induced pluripotent stem cell lines derived from human somatic cells. Science 2007; 318:1917-1920

6. Xu J, Du Y, Deng H. Direct lineage reprogramming: strategies, mechanisms, and applications. Cell Stem Cell 2015; 16:119-134
7. Sancho-Martinez I, Baek SH, Izpisua Belmonte JC. Lineage conversion methodologies meet the reprogramming toolbox. Nat Cell Biol 2012;14:892-899

8. Yu C, Liu K, Tang S, Ding S. Chemical approaches to cell reprogramming. Curr Opin Genet Dev 2014;28:50-56

9. Jung DW, Kim WH, Williams DR. Reprogram or reboot: small molecule approaches for the production of induced pluripotent stem cells and direct cell reprogramming. ACS Chem Biol 2014;9:80-95

10. Higuchi A, Ling QD, Kumar SS, Munusamy MA, Alarfaj AA, Chang Y, Kao SH, Lin KC, Wang HC, Umezawa A. Generation of pluripotent stem cells without the use of genetic material. Lab Invest 2015;95:26-42

11. Schlaeger TM, Daheron L, Brickler TR, Entwisle S, Chan K, Cianci A, DeVine A, Ettenger A, Fitzgerald K, Godfrey M, Gupta D, McPherson J, Malwadkar P, Gupta M, Bell B, Doi A, Jung N, Li X, Lynes MS, Brookes E, Cherry AB, Demirbas D, Tsankov AM8, Zon LI, Rubin LL, Feinberg AP, Meissner A, Cowan CA, Daley GQ. A comparison of non-integrating reprogramming methods. Nat Biotechnol 2015;33:58-63

12. González F, Boué S, Izpisúa Belmonte JC. Methods for making induced pluripotent stem cells: reprogramming à la carte. Nat Rev Genet 2011;12:231-242

13. Zhou YY, Zeng F. Integration-free methods for generating induced pluripotent stem cells. Genomics Proteomics Bioinformatics 2013;11:284-287

14. Goh PA, Caxaria S, Casper C, Rosales C, Warner TT, Coffey PJ, Nathwani AC. A systematic evaluation of integration free reprogramming methods for deriving clinically relevant patient specific induced pluripotent stem (iPS) cells. PLoS One 2013;8:e81622

15. Silva M, Daheron L, Hurley H, Bure K, Barker R, Carr AJ, Williams D, Kim HW, French A, Coffey PJ, Cooper-White JJ, Reeve B, Rao M, Snyder EY, Ng KS, Mead BE, Smith JA, Karp JM, Brindley DA, Wall I. Generating iPSCs: translating cell reprogramming science into scalable and robust biomanufacturing strategies. Cell Stem Cell 2015;16:13-17

16. Li W, Jiang K, Ding S. Concise review: A chemical approach to control cell fate and function. Stem Cells 2012;30:61-68

17. Li W, Jiang K, Wei W, Shi Y, Ding S. Chemical approaches to studying stem cell biology. Cell Res 2013; 23:81-91

18. Li W, Li K, Wei W, Ding S. Chemical approaches to stem cell biology and therapeutics. Cell Stem Cell 2013;13: 270-283

19. Li X, Zuo X, Jing J, Ma Y, Wang J, Liu D, Zhu J, Du X, Xiong L, Du Y, Xu J, Xiao X, Wang J, Chai Z, Zhao Y, Deng H. Small-Molecule-Driven Direct Reprogramming of Mouse Fibroblasts into Functional Neurons. Cell Stem Cell 2015;17:195-203

20. Davies SG, Kennewell PD, Russell AJ, Seden PT, Westwood R, Wynne GM. Stemistry: the control of stem cells in situ using chemistry. J Med Chem 2015;58:2863- 
2894

21. Cheng L, Hu W, Qiu B, Zhao J, Yu Y, Guan W, Wang $M$, Yang W, Pei G. Generation of neural progenitor cells by chemical cocktails and hypoxia. Cell Res 2014;24: 665-679

22. Hu W, Qiu B, Guan W, Wang Q, Wang M, Li W, Gao L, Shen L, Huang Y, Xie G, Zhao H, Jin Y, Tang B, Yu Y, Zhao J, Pei G. Direct conversion of normal and Alzheimer's disease human fibroblasts into neuronal cells by small molecules. Cell Stem Cell 2015;17:204-212

23. Pennarossa G, Maffei S, Campagnol M, Tarantini L, Gandolfi F, Brevini TA. Brief demethylation step allows the conversion of adult human skin fibroblasts into insulin-secreting cells. Proc Natl Acad Sci U S A 2013; 110:8948-8953

24. Sayed N, Wong WT, Ospino F, Meng S, Lee J, Jha A, Dexheimer P, Aronow BJ, Cooke JP. Transdifferentiation of human fibroblasts to endothelial cells: role of innate immunity. Circulation 2015;131:300-309

25. Hou P, Li Y, Zhang X, Liu C, Guan J, Li H, Zhao T, Ye J, Yang W, Liu K, Ge J, Xu J, Zhang Q, Zhao Y, Deng H. Pluripotent stem cells induced from mouse somatic cells by small-molecule compounds. Science 2013;341:651-654

26. Zhang L, Yin JC, Yeh H, Ma NX, Lee G, Chen XA, Wang Y, Lin L, Chen L, Jin P, Wu GY, Chen G. Small molecules efficiently reprogram human astroglial cells into functional neurons. Cell Stem Cell 2015;17:735-747

27. Fu Y, Huang C, Xu X, Gu H, Ye Y, Jiang C, Qiu Z, Xie $\mathrm{X}$. Direct reprogramming of mouse fibroblasts into cardiomyocytes with chemical cocktails. Cell Res 2015;25: 1013-1024

28. Long Y, Wang M, Gu H, Xie X. Bromodeoxyuridine promotes full-chemical induction of mouse pluripotent stem cells. Cell Res 2015;25:1171-1174

29. Zhao Y, Zhao T, Guan J, Zhang X, Fu Y, Ye J, Zhu J, Meng G, Ge J, Yang S, Cheng L, Du Y, Zhao C, Wang T, Su L, Yang W, Deng H. A XEN-like state bridges somatic cells to pluripotency during chemical reprogramming. Cell 2015;163:1678-1691

30. Ye J, Ge J, Zhang X, Cheng L, Zhang Z, He S, Wang Y, Lin H, Yang W, Liu J, Zhao Y, Deng H. Pluripotent stem cells induced from mouse neural stem cells and small intestinal epithelial cells by small molecule compounds. Cell Res 2016;26:34-45

31. Cheng L, Gao L, Guan W, Mao J, Hu W, Qiu B, Zhao J, Yu Y, Pei G. Direct conversion of astrocytes into neuronal cells by drug cocktail. Cell Res 2015;25:1269-1272

32. Federation AJ, Bradner JE, Meissner A. The use of small molecules in somatic-cell reprogramming. Trends Cell Biol 2014;24:179-187

33. Wijdeven RH, Neefjes J, Ovaa H. How chemistry supports cell biology: the chemical toolbox at your service. Trends Cell Biol 2014;24:751-760

34. Babos K, Ichida JK. Small molecules take a big step by converting fibroblasts into neurons. Cell Stem Cell 2015;17:127-129
35. Guo Z, Zhang L, Wu Z, Chen Y, Wang F, Chen G. In vivo direct reprogramming of reactive glial cells into functional neurons after brain injury and in an Alzheimer's disease model. Cell Stem Cell 2014;14:188-202

36. Heinrich C, Bergami M, Gascón S, Lepier A, Viganò F, Dimou L, Sutor B, Berninger B, Götz M. Sox2-mediated conversion of NG2 glia into induced neurons in the injured adult cerebral cortex. Stem Cell Reports 2014;3:1000-1014

37. Grande A, Sumiyoshi K, López-Juárez A, Howard J, Sakthivel B, Aronow B, Campbell K, Nakafuku M. Environmental impact on direct neuronal reprogramming in vivo in the adult brain. Nat Commun 2013;4:2373

38. Liu Y, Miao Q, Yuan J, Han S, Zhang P, Li S, Rao Z, Zhao W, Ye Q, Geng J, Zhang X, Cheng L. Ascll converts dorsal midbrain astrocytes into functional neurons in vivo. J Neurosci 2015;35:9336-9355

39. Torper O, Pfisterer U, Wolf DA, Pereira M, Lau S, Jakobsson J, Björklund A, Grealish S, Parmar M. Generation of induced neurons via direct conversion in vivo. Proc Natl Acad Sci U S A 2013;110:7038-7043

40. Niu W, Zang T, Zou Y, Fang S, Smith DK, Bachoo R, Zhang CL. In vivo reprogramming of astrocytes to neuroblasts in the adult brain. Nat Cell Biol 2013;15:1164-1175

41. Vidal SE, Amlani B, Chen T, Tsirigos A, Stadtfeld M. Combinatorial modulation of signaling pathways reveals cell-type-specific requirements for highly efficient and synchronous iPSC reprogramming. Stem Cell Reports 2014;3: 574-584

42. Ebrahimi B. Reprogramming barriers and enhancers: strategies to enhance the efficiency and kinetics of induced pluripotency. Cell Regen (Lond) 2015;4:1-12

43. Mohyeldin A, Garzón-Muvdi T, Quiñones-Hinojosa A. Oxygen in stem cell biology: a critical component of the stem cell niche. Cell Stem Cell 2010;7:150-161

44. Ieda $M, F u$ JD, Delgado-Olguin P, Vedantham V, Hayashi Y, Bruneau BG, Srivastava D. Direct reprogramming of fibroblasts into functional cardiomyocytes by defined factors. Cell 2010;142:375-386

45. Fu JD, Stone NR, Liu L, Spencer CI, Qian L, Hayashi Y, Delgado-Olguin P, Ding S, Bruneau BG, Srivastava D. Direct reprogramming of human fibroblasts toward a cardiomyocyte-like state. Stem Cell Reports 2013;1:235-247

46. Efe JA, Hilcove S, Kim J, Zhou H, Ouyang K, Wang G, Chen J, Ding S. Conversion of mouse fibroblasts into cardiomyocytes using a direct reprogramming strategy. Nat Cell Biol 2011;13:215-222

47. Jayawardena TM, Egemnazarov B, Finch EA, Zhang L, Payne JA, Pandya K, Zhang Z, Rosenberg P, Mirotsou M, Dzau VJ. MicroRNA-mediated in vitro and in vivo direct reprogramming of cardiac fibroblasts to cardiomyocytes. Circ Res 2012;110:1465-1473

48. Wang H, Cao N, Spencer CI, Nie B, Ma T, Xu T, Zhang Y, Wang X, Srivastava D, Ding S. Small molecules enable cardiac reprogramming of mouse fibroblasts with a single factor, Oct4. Cell Rep 2014;6:951-960

49. Ebrahimi B. Engineering Cell Fate: The roles of iPSC tran- 
scription factors, chemicals, barriers and enhancing factors in reprogramming and transdifferentiation. bioRxiv 2015. doi: 10.1101/019455.

50. Lee J, Sayed N, Hunter A, Au KF, Wong WH, Mocarski ES, Pera RR, Yakubov E, Cooke JP. Activation of innate immunity is required for efficient nuclear reprogramming. Cell 2012;151:547-558

51. Kurian L, Sancho-Martinez I, Nivet E, Aguirre A, Moon K, Pendaries C, Volle-Challier C, Bono F, Herbert JM, Pulecio J, Xia Y, Li M, Montserrat N, Ruiz S, Dubova I, Rodriguez C, Denli AM, Boscolo FS, Thiagarajan RD, Gage FH, Loring JF, Laurent LC, Izpisua Belmonte JC. Conversion of human fibroblasts to angioblast-like progenitor cells. Nat Methods 2013;10:77-83

52. Margariti A, Winkler B, Karamariti E, Zampetaki A, Tsai TN, Baban D, Ragoussis J, Huang Y, Han JD, Zeng L, Hu Y, Xu Q. Direct reprogramming of fibroblasts into endothelial cells capable of angiogenesis and reendothelialization in tissue-engineered vessels. Proc Natl Acad Sci U S A 2012;109:13793-13798

53. Li J, Huang NF, Zou J, Laurent TJ, Lee JC, Okogbaa J, Cooke JP, Ding S. Conversion of human fibroblasts to functional endothelial cells by defined factors. Arterioscler Thromb Vasc Biol 2013;33:1366-1375

54. Ginsberg M, James D, Ding BS, Nolan D, Geng F, Butler JM, Schachterle W, Pulijaal VR, Mathew S, Chasen ST,
Xiang J, Rosenwaks Z, Shido K, Elemento O, Rabbany SY, Rafii S. Efficient direct reprogramming of mature amniotic cells into endothelial cells by ETS factors and TGF $\beta$ suppression. Cell 2012;151:559-575

55. Lee AS, Tang C, Rao MS, Weissman IL, Wu JC. Tumorigenicity as a clinical hurdle for pluripotent stem cell therapies. Nat Med 2013;19:998-1004

56. Xu T, Zhang $M$, Laurent $T$, Xie $M$, Ding $S$. Concise review: chemical approaches for modulating lineage-specific stem cells and progenitors. Stem Cells Transl Med 2013;2: 355-361

57. Ebrahimi B. Biological computational approaches: new hopes to improve (re)programming robustness, regenerative medicine and cancer therapeutics. Differentiation 2016. doi: 10.1016/j.diff.2016.03.001

58. Qian L, Huang Y, Spencer CI, Foley A, Vedantham V, Liu L, Conway SJ, Fu JD, Srivastava D. In vivo reprogramming of murine cardiac fibroblasts into induced cardiomyocytes. Nature 2012;485:593-598

59. Inagawa $\mathrm{K}$, Miyamoto $\mathrm{K}$, Yamakawa $\mathrm{H}$, Muraoka $\mathrm{N}$, Sadahiro T, Umei T, Wada R, Katsumata Y, Kaneda R, Nakade K, Kurihara C, Obata Y, Miyake K, Fukuda K, Ieda $M$. Induction of cardiomyocyte-like cells in infarct hearts by gene transfer of Gata4, Mef2c, and Tbx5. Circ Res 2012;111:1147-1156 